\title{
Características de Estrutura de Personalidade de Pais e Mães Envolvidos no Fenômeno da Alienação Parental
}

\author{
Fabiana da Motta Damiani ${ }^{1}$ \\ Tribunal de Justiça do Rio Grande do Sul \\ Vera Regina Rohnelt Ramires ${ }^{2}$ \\ Universidade do Vale do Rio dos Sinos (UNISINOS)
}

\begin{abstract}
RESUMO
A Alienação Parental é um fenômeno que tem sido observado associado ao divórcio altamente conflitivo. Esse estudo investigou as características de estrutura de personalidade de pais e mães envolvidos nesse fenômeno. Foi utilizada uma abordagem qualitativo-exploratória, adotando-se o procedimento de estudos de caso múltiplos. Foram realizadas entrevistas estruturadas e semiestruturadas, além da aplicação do Método Rorschach, por meio do sistema compreensivo. Os resultados apontaram para a presença de defesas primitivas, intensa ansiedade de separação, predominância de vínculos simbióticos, dificuldade de discriminação e percepção inadequada do outro.
\end{abstract}

Palavras-chave: Alienação Parental; divórcio; personalidade; Rorschach.

\section{ABSTRACT \\ Personality Structure Traits of the Fathers and Mothers Involved in the Parental Alienation Phenomenon}

Parental Alienation is a phenomenon that has been observed associated with highly conflicting divorces. The present study investigated the personality structure traits of fathers and mothers involved in this phenomenon. A qualitative-exploratory approach was used together with a multiple case study procedure. Structured and semi-structured interviews were performed, along with the application of the Rorschach Method by means of the comprehensive system. Results indicated the presence of primitive defenses, intense separation anxiety and predominance of symbiotic bonding, difficulty of discrimination and inadequate perception of others.

Keywords: Parental Alienation, divorce, personality; Rorschach.

O foco deste estudo foram as características de estrutura de personalidade de pais e mães envolvidos no fenômeno da Alienação Parental. $O$ conceito de Alienação Parental foi objeto de análise, inicialmente, pelo psiquiatra norte-americano Richard Gardner na década de oitenta. Em seu trabalho, como pesquisador da Universidade de Columbia, nos Estados Unidos, e psicoterapeuta de crianças e adolescentes, observou um comportamento que pensou ser resultado de uma "programação" ou "campanha" de um dos pais em relação aos seus filhos, direcionada ao rechaço do outro genitor. Nessa situação, consequentemente, os filhos passavam a apresentar uma rejeição importante em relação a um de seus pais. O contexto do divórcio altamente conflitivo foi identificado como sendo o momento mais propício para tais comportamentos aparecerem, e a contribuição da criança foi descrita como significativa (Gardner, 1987).
Gardner (1987) estabeleceu uma descrição do fenômeno da Alienação Parental e foi ainda mais longe, propondo a definição de uma síndrome. Para o autor, a Alienação Parental consiste no processo de programar uma criança para que odeie um de seus genitores, sem que haja uma justificativa aparente ou real. Nessa perspectiva, a Síndrome de Alienação Parental (SAP) é um fenômeno focado no comportamento da criança, que tem um papel ativo na produção do resultado. $\mathrm{O}$ fenômeno tem como principal característica o rechaço ao genitor alienado, com o consequente afastamento deste, e o reforço da ligação com o outro genitor, descrito como alienador.

O conceito de Alienação Parental ainda é incipiente e vem enfrentando muitas críticas e controvérsias (Bernet, 2008; Bone, 2003; Darnall, 1997; Emery, 2005; Escudero, Aguilar \& La Cruz, 2008). Esses autores criticaram a utilização do termo Síndrome para 
a descrição de um fenômeno clínico. Apesar das críticas, outros estudos evidenciaram a existência do fenômeno com indicadores evidenciando que entre $20 \mathrm{e}$ $40 \%$ das crianças envolvidas em disputas de guarda desenvolvem sintomas característicos de Alienação Parental (Kopetski, 1998; Stokkers \& Kormos, 2005).

$\mathrm{Na}$ tentativa de obter uma maior compreensão do fenômeno, Darnall (1997) mencionou a importância de se observarem as características individuais dos pais alienadores, descrevendo-os assim: o ingênuo, o ativo e/ou o obcecado. De acordo com essa descrição, o ingênuo é mais passivo; o ativo é vulnerável à perda de controle e o obcecado é alguém determinado a destruir o ex-cônjuge. Essa é outra maneira de compreensão do fenômeno, que contempla a existência de um ciclo de alienação em que pais e filhos ficam retidos em sua dinâmica. Trata-se de um fenômeno em que cada um tem seu papel na eclosão e manutenção do conflito (Darnall, 2010).

As características do fenômeno da Alienação Parental incluem uma campanha para denegrir um dos pais, com justificativas inadequadas, ausência de ambivalência, apoio reflexivo ao genitor alienador e ausência de culpa. É comum ainda, o uso de argumentos que parecem ensaiados, com linguagem não própria das crianças, mas que elas assumem como suas (Darnall, 1997; Gardner, 1998).

Alguns autores relacionaram a falsa denúncia de abuso sexual com o fenômeno da Alienação Parental (Bow, Quinnell \& Zarof, 2002; Dias, 2006; Gudjonsson, 1983). Nessa situação, a narrativa de um episódio, durante o período de visitas, que possa configurar indícios de tentativa de aproximação incestuosa é levada ao extremo. O que ocorre, na maioria das vezes, é a amplificação da narrativa, transformando o fato, verdadeiro ou não, em uma denúncia de incesto. $O$ filho passa a ser convencido da existência de um fato e levado a repetir o que lhe é afirmado como tendo realmente acontecido. Assim, a criança passa a viver uma história falsa, com falsos personagens, mas que é sentida como verdadeira. Tratase de uma memória que resulta de uma sugestão externa. A este fenômeno dá-se o nome de implantação de falsas memórias (Stein \& Perguer, 2001; Stein, Feix \& Rohenkohl, 2006).

O comportamento alienador pode estar associado a características perversas dos pais, com a presença de uma forma de agir premeditada, com o intuito de prejudicar seu ex-cônjuge (Aguilar, 2007). Essa é uma visão que dicotomiza a relação em termos de uma vítima (genitor alienado) e um culpado (genitor alienador). Entretanto, em muitos casos, ambos os genitores estão predispostos a alienar, em função de características de personalidade não adaptativas (Darnall, 2010). Assim, é possível discutir o fenômeno pensando nas características de personalidade dos pais, sem que haja necessariamente uma vítima ou um culpado.

As características individuais dos envolvidos no fenômeno da Alienação Parental têm sido mencionadas em alguns estudos, destacando-se uma maior ocorrência de mães no papel de alienadoras (Bala, Hunt \& MacCarney, 2010; Berns, 2001; Calabrese, Miller \& Dooley, 1987; Dunne \& Hedrick, 1994; Johnston, 2003). As pesquisas apontaram características que influenciam na ocorrência do fenômeno da Alienação Parental. Muitos genitores alienadores possuem traços de isolamento, impotência, problemas de desenvolvimento e agem a partir de uma ferida narcísica como força motivadora. Além disso, sentimentos de rivalidade, disputa de interesses e sentimentos de vingança em relação ao ex-cônjuge também são comuns (Cruz, Maciel \& Ramires, 2005).

$\mathrm{O}$ discurso negativo e maldoso por parte do alienador e a consequente indução de conflitos entre a criança e o genitor alienado é outra característica importante encontrada na dinâmica da Alienação Parental. A literatura aponta que, quase sempre, há uma vivência de redução no contato com os filhos e na visitação a eles. Como explicação para tais comportamentos, estão a presença de indicativos de defesas primitivas, como a cisão e a identificação projetiva (Baker \& Darnall, 2006; Gordon \& Botinelli, 2008; Vassilou \& Cartwright, 2001).

A estrutura de personalidade, na concepção psicanalítica, leva em conta os aspectos constitucionais, as experiências emocionais na infância e as experiências traumáticas na vida adulta (Freud, 1916/1994). A contribuição de Bergeret (1988) na compreensão da personalidade demonstrou que ela está organizada de modo estável, com mecanismos de defesa, modos de relação de objeto e um grau definido de evolução libidinal e egóica.

Segundo Bergeret (1998), as personalidades neuróticas e psicóticas podem ser descritas como estruturas, enquanto os estados-limite constituem uma organização e não chegam a se constituir como autênticas estruturas. Os estados-limite correspondem às personalidades limítrofes ou borderlines. $\mathrm{O}$ autor salientou que a estrutura é irreversível, porém a 
organização pode ser provisória. Como critérios para essa classificação, são levados em conta os seguintes fatores: natureza do conflito predominante, natureza da angústia predominante, principais defesas e relação de objeto. Nessa perspectiva, torna-se importante observar um padrão duradouro ao longo do tempo, que direciona ao caminho da estruturação da personalidade. Essa abordagem baseia-se nos aspectos dinâmicos formadores da personalidade e diferencia-se das abordagens categoriais do DSM V e da CID 10 (Kernberg, 1995).

A avaliação da personalidade em processos de guarda é fundamental para uma melhor compreensão de fenômenos como a Alienação Parental. O Método Rorschach vem sendo apontado como um instrumento adequado para utilização no âmbito Forense, mais especificamente em processos de guarda. A confiabilidade no teste baseia-se em pesquisas empíricas, principalmente aquelas relacionadas à validação e normatização (Rovinski, 2007; Singer, Hoppe, Lee \& Walters, 2008; Villemor-Amaral \& Pasqualini-Casado, 2006).

Rovisnki (2011), ao abordar o uso do Método Rorschach em processos de guarda, mencionou alguns dados que devem receber atenção especial. Segundo a autora, é preciso observar como se apresentam as desordens do pensamento, a leitura da realidade, o humor, a cognição e o grau de ansiedade. Outros estudos com o Método Rorschach em disputas de guarda demonstraram a presença de um número elevado de respostas personalizadas e resistência frente à tarefa do teste (Singer, Hoppe, Lee \& Walters, 2008).

Ao revisar a temática de Alienação Parental foi possível observar que a maioria dos estudos mencionou a possibilidade da existência de manipulação de um dos genitores em relação aos filhos no processo do divórcio altamente conflitivo. As características individuais dos envolvidos são descritas associadas ao fenômeno da Alienação Parental; porém, esse tema ainda precisa ser investigado para a compreensão de como essas características podem ou não influenciar na ocorrência do fenômeno.

É importante salientar também, que os estudos relacionados à Psicologia Jurídica ainda representam uma lacuna em termos de literatura técnica no Brasil (França, 2004; Lago \& Bandeira, 2009; Rovinski, 2007). O fenômeno da Alienação Parental vem sendo pouco explorado em pesquisas empíricas, o que justifica a realização deste estudo, cujo objetivo foi analisar e compreender as características de estrutura de personalidade de pais e mães envolvidos no fenômeno da Alienação Parental.

\section{MÉTODO}

\section{Participantes}

Participaram deste estudo três homens e três mulheres, ex-casais em disputa de guarda de filhos envolvidos no fenômeno da Alienação Parental. A caracterização dos participantes encontra-se na tabela 1 . Os critérios utilizados para identificar a classe social dos participantes foram os adotados pelo Centro de Políticas Sociais da Fundação Getúlio Vargas (2012).

\section{Procedimentos de coleta de dados}

$\mathrm{O}$ estudo teve um delineamento qualitativoexploratório, com a utilização da técnica de estudos de casos múltiplos (Yin, 2005). Os participantes haviam sido encaminhados a uma clínica escola de uma universidade do sul do país pelo Poder Judiciário para avaliação psicológica. Antes de realizar a avaliação psicológica solicitada pelo Poder Judiciário, os participantes foram consultados sobre sua disponibilidade de realizar as entrevistas para a pesquisa.

Inicialmente, foram realizadas entrevistas semiestruturadas na forma individual com os participantes. Essas entrevistas investigaram os motivos

Tabela 1

Identificação dos participantes

\begin{tabular}{lllll}
\hline Nome & Idade & Escolaridade & Classe Social & Idade dos Filhos \\
\hline Dora & 35 & E. Fundamental Incompleto & Classe E & 8 anos \\
José & 46 & E. Fundamental Incompleto & Classe E & 8 anos \\
Beatriz & 32 & E. Médio Completo & Classe C & 10 e 6 anos \\
João & 41 & E. Médio Completo & Classe C & 10 e 6 anos \\
Taís & 23 & E. Médio Completo & Classe E & 6 anos \\
Marcelo & 28 & E. Fundamental Incompleto & Classe E & 6 anos \\
\hline
\end{tabular}


que levaram à separação, condições atuais do relacionamento familiar, nível do conflito, descrição do vínculo dos filhos com cada genitor antes, durante $\mathrm{e}$ depois da separação ou divórcio. Posteriormente, foi realizada uma entrevista estruturada com cada um, com o objetivo de obter maiores informações sobre sua história, bem como situações importantes vivenciadas ao longo da vida ligadas aos seus relacionamentos significativos (Cunha, 2003; Flick, 2009). Em seguida, o Método Rorschach foi aplicado, o instrumento foi codificado e interpretado a partir do Sistema Compreensivo de Exner (1999). A análise das variáveis foi realizada com base em estudos normativos para a população brasileira (Nascimento, 2010). As entrevistas e a aplicação do Método Rorschach foram realizadas por duas pesquisadoras, respectivamente.

O projeto foi submetido ao Comitê de Ética em Pesquisa da universidade à qual se vinculam as pesquisadoras e foi aprovado. Os participantes assinaram o Termo de Consentimento Livre e Esclarecido. Todos os nomes, assim como quaisquer informações que permitissem identificar os participantes, foram modificados.

\section{Procedimentos de análise de dados}

$\mathrm{Na}$ primeira etapa, foi realizada uma descrição abrangente de cada caso, organizada de forma cronológica (seguindo os eventos importantes da história de vida dos participantes) e temática (identificando as categorias relevantes para o estudo em questão: indicadores de Alienação Parental, história do conflito conjugal, funcionamento psicodinâmico e características da estrutura de personalidade dos envolvidos). Nessa etapa, foram analisadas as entrevistas juntamente com os resultados do Método Rorschach. Na Segunda etapa, foi utilizada a técnica de Construção da Explanação (Yin, 2005). Na terceira etapa, foi utilizada a técnica de Síntese de Casos Cruzados (Yin, 2005), com o objetivo de verificar convergências e divergências acerca da temática investigada.

\section{RESULTADOS E DISCUSSÃO}

\section{Caso 1: Dora e José}

Dora e José são pais de Mariana, que tinha 8 anos na ocasião da avaliação e residia com a mãe. A separação do casal ocorreu antes do nascimento da menina. A união durou cerca de seis meses, porém, após o nascimento da filha, encontravam-se esporadicamente.
O rompimento definitivo ocorreu quando Mariana estava com 4 anos. Na ocasião, os pais discutiram a guarda da menina na justiça. O pai entrou com uma ação alegando que a mãe maltratava a criança e dificultava o seu contato com ela. A mãe da menina, por sua vez, acusou o pai de abuso sexual.

A história de ambos os pais foi marcada por perdas precoces e significativas. José perdeu seu pai aos 6 anos de forma traumática, em um acidente presenciado por ele. Descreveu a figura paterna como um "pai bom e trabalhador" e salientou que "foi muito triste" presenciar a morte dele. Sua mãe faleceu quando ele estava com 20 anos.

José aparentou ficar bastante mobilizado ao relembrar a perda de sua mãe: "foi a mesma coisa que tirar um pedaço de mim". Logo após a morte dela se casou, pois tinha que "tocar a vida", unindo-se a uma prima, de quem se separou. O motivo dessa separação foi uma traição de sua ex-mulher. José ficou com a guarda de seus filhos e a separação ocorreu em meio a uma disputa judicial.

Dora também relatou uma história de vida sofrida. Quando tinha 2 anos de idade, seus pais se separaram em função de uma traição de seu pai. Seus sentimentos em relação à separação deles demonstraram que ela acreditou que o pai "preferiu ficar com a outra" abandonando a mãe e os filhos. Dora passou a vida longe dele, encontrando-o novamente somente na idade adulta.

Durante as entrevistas, Dora chorou ao narrar a infância longe do pai, demonstrando muito ressentimento com esta situação. Costumava ouvir, quando pequena, que "seu pai aprontou para sua mãe, botando outra para dentro de casa". Seus relatos evidenciaram uma desvalorização da figura paterna, enquanto a figura materna foi descrita como alguém que "supriu a falta do pai, uma amiga, que sempre dava bons conselhos".

Dora foi casada antes de conhecer José, e o relacionamento terminou durante a gestação de seu primeiro filho. Demonstrou muita dificuldade em se distanciar da figura materna, já que, em nenhum dos seus relacionamentos, conseguiu se desvincular da presença da mãe. Seus relatos evidenciaram a participação constante de sua mãe nas decisões importantes de sua vida, inclusive naquelas que diziam respeito aos seus relacionamentos afetivos.

Os motivos que levaram à separação de José, segundo Dora, referem-se ao fato dele não ter aceitado 
a gestação de Mariana, pedindo-lhe que fizesse um aborto. Ela também mencionou uma traição, ocasião em que teria ido chorar na casa de sua mãe. Contou que sua mãe não gostava de José e sempre enfatizou sua opinião de que o relacionamento dos dois "não iria dar certo". José alegou como motivo do rompimento, o comportamento instável de Dora e a dificuldade dela em aceitar a convivência com os dois filhos do seu primeiro casamento.

Os indicadores de Alienação Parental que se apresentaram foram o discurso da mãe, denegrindo a imagem do genitor, inclusive acusando-o de abuso sexual sem que houvesse provas ou indícios da veracidade da acusação (mãe relatou ter encontrado pelos e manchas no meio das pernas da menina). A extensão da animosidade à família foi outro indicador presente, já que a sogra de José também apresentava um comportamento de rechaço em relação à presença dele na vida da filha e da neta. Com o tempo, José passou a ter muitas dificuldades para ver Mariana, e, no momento da avaliação, as visitas não estavam ocorrendo. $\mathrm{O}$ discurso de Mariana, durante as entrevistas, foi considerado ensaiado e com verbalizações que não são típicas das crianças de sua idade.

A análise do Método Rorschach indicou que José possui poucos recursos cognitivos. Os índices apontaram para uma estrutura de personalidade na qual há um excessivo controle. Desta forma, ele pareceu se utilizar de mecanismos de defesa como a repressão, por possuir dificuldades de elaboração das vivências traumáticas. Este indicador sugeriu que esta é uma forma de evitar maiores sofrimentos e uma desorganização de seu mundo interno.

Foi possível observar, ainda, o índice de depressão positivo e a constelação de suicídio com sete variáveis presentes (encontrando-se no ponto de corte; para ser positivo, são necessárias oito variáveis). Neste caso específico, a depressão e a constelação de suicídio pareceram estar associadas aos sentimentos de desesperança em relação ao relacionamento com sua filha. Ao se sentir uma vítima, José reagiu se deprimindo. Apresentou um índice de egocentrismo baixo, associado a prejuízos em captar as informações. Os dados do Rorschach revelaram que José é uma pessoa com condições adequadas de manter vínculos afetivos, aparentando ter necessidade de trocas afetivas. Esse é um dado que reforça a ideia de que ele é um pai que buscou a justiça por ter uma forte ligação com sua filha.
A análise do Rorschach demonstrou também sentimentos de baixa autoestima, associados a vivências de desamparo. Há uma distorção na percepção do outro e uma característica mais evitativa no âmbito relacional. Esses dados são sugestivos de um estado em que as demandas do mundo externo são maiores do que ele pode suportar. Neste sentido, os resultados do teste demonstraram o quanto José se sentia perturbado, justamente por estar sofrendo com a ausência da filha e com as acusações de abuso.

A análise qualitativa de suas respostam evidenciaram que José vem lutando contra sentimentos de hostilidade e ressentimento e que se sente mobilizado frente às denúncias de sua ex-mulher. Apresentou respostas de ferimento, machucado e sangue, demonstrando, através da projeção, suas fantasias em relação à acusação de abuso sexual.

Em relação à Dora, o Método Rorschach apontou um resultado muito semelhante ao de seu excompanheiro. O índice de depressão foi positivo, acompanhado da constelação de suicídio com sete variáveis positivas. $\mathrm{O}$ fato de Dora ter se deprimido pode indicar que sua vivência em relação a José foi a de uma ameaça real. Porém, apresentou uma distorção na percepção do outro e indicadores que remetem a características de imaturidade e infantilidade. Outros indicadores apontaram um funcionamento regressivo, com prejuízos na capacidade de discriminação (Viglione, 2004)

Os dados apontaram para um vazio relacional, que parece ter origem na relação simbiótica com sua mãe. Apesar de não apresentar indicadores típicos de ruptura com a realidade, há indícios de que, ao se sentir ameaçada em seu núcleo patológico (núcleo simbiótico), pode perder o controle e romper com a realidade. O teste demonstrou que Dora possui um excessivo apego às suas próprias ideias. Segundo Exner e Sendín (1999) este é um indicador encontrado frequentemente em casais que brigam na justiça.

A análise qualitativa de suas respostas demonstrou que seus vínculos afetivos aparecem como frágeis e danificados. Na lâmina materna (Weiner, 2000), apresentou respostas de dois seres com cabeça de animais e com um vazio entre eles. Estes seres foram apresentados se olhando, mas com os corpos direcionados para lados opostos. Esta resposta evidenciou uma vivência primitiva e regressiva da relação com a mãe, podendo se estender para os outros vínculos afetivos. Suas respostas reforçaram a ideia de 
dificuldades para se vincular, uma vez que pareceu se sentir fusionada à mãe.

Em relação à dinâmica do relacionamento do casal, foram observadas algumas características importantes. Tanto Dora quanto José viveram em famílias desfeitas por perdas precoces: ela, pela separação de seus pais e ele, pela perda traumática do pai. Após esses eventos, ambos se ligaram de forma intensa à figura materna. No caso de Dora, foi possível cogitar a hipótese de que tenha vivido uma situação de Alienação Parental durante a separação de seus pais. Desta forma, o carinho e atenção do pai José em relação à filha Mariana pode ter suscitado em Dora um sentimento de ameaça, afastando drasticamente o pai da vida da menina.

\section{Caso 2: Beatriz e João}

O casamento de João e Beatriz durou aproximadamente treze anos, e eles tiveram dois filhos, Bruno e Ana que, na ocasião da avaliação, estavam com 10 e 6 anos, respectivamente. A união do casal foi marcada por brigas e desentendimentos. No momento da avaliação, disputavam a guarda dos filhos. As crianças estavam residindo com a mãe e as visitas ao pai não estavam ocorrendo. A separação ocorreu de forma tumultuada, com acusações mútuas, ambos admitiram que o relacionamento foi bastante conturbado, com brigas constantes presenciadas pelos filhos.

João foi criado no interior do estado em uma família com valores rígidos. Começou a trabalhar muito cedo, na roça, auxiliando seu pai. Descreveu sua mãe como uma pessoa boa e carinhosa. No entanto, sempre se sentiu mais próximo do pai, que segundo ele, era um homem honesto e trabalhador. Aos 17 anos saiu de casa para trabalhar em uma atividade que exerce até hoje.

Seus pais haviam se separado há treze anos, no momento da avaliação, em função do alcoolismo de seu pai. Seus pais levavam uma vida simples e João mantinha relacionamento com ambos. Porém, costumava vê-los esporadicamente, por não residirem na mesma cidade que ele. Mesmo assim, costumava ajudá-los financeiramente sempre que precisavam.

Já Beatriz teve uma infância marcada pelo desamparo dos pais, que delegaram seus cuidados a um irmão doze anos mais velho que ela. Seus relatos evidenciaram uma relação de intensa dependência com este irmão, que morreu quando Beatriz tinha 12 anos. Sua revolta nessa ocasião foi tão grande que, ao voltar do enterro, quebrou todo o quarto do irmão. Sentiu muita raiva por ter sido "abandonada" por ele. Após a perda, voltou-se para os pais, como substitutos da figura do irmão.

Beatriz relatou que teve "problemas" após a morte do irmão, pois seus pais ficaram "perdidos" em relação à sua educação. Na ocasião, entrou em "crise", pois considerava seu irmão "pai, mãe, amigo, tudo". Teve muita dificuldade em aceitar os limites que seus pais tentavam the impor. Em função disso, brigas $\mathrm{e}$ desentendimentos aconteciam com frequência. Com 17 anos se casou pela primeira vez, contra a vontade de seus pais, e essa união durou sete meses. Quando decidiu se separar, teve o apoio de seu pai que, nessa ocasião, "virou seu melhor amigo".

Sobre o relacionamento conjugal, ambos relataram muitas brigas e um ambiente difícil em casa. O casal estava separado quando Beatriz descobriu que estava grávida do primeiro filho. Reataram logo em seguida, mas ela o acusou de ter rejeitado o menino, pedindo que fizesse um aborto. Durante a união, tiveram várias separações, com histórico de agressões mútuas, muitas delas registradas na polícia.

Beatriz acusou João de ter um temperamento difícil. Segundo ela, ele a agredia, a traía e tratava mal o filho mais velho. $\mathrm{Na}$ ocasião do rompimento definitivo, durante uma briga, Beatriz chamou a polícia alegando que João teria se descontrolado e quebrado vários objetos em casa. João, por sua vez, afirmou que foi vítima de uma "armação" e que Beatriz teria puxado uma toalha de mesa, derrubado objetos e saído correndo chamando por "socorro".

Entre os indicadores de Alienação Parental, foi possível observar o discurso de Beatriz denegrindo a imagem de João. Isso ficou evidente nas entrevistas, nas quais se ocupou mais em narrar o comportamento de seu ex-marido do que em falar dela própria. A linguagem das crianças também foi considerada ensaiada e não própria para a idade (a filha mais nova narrou os acontecimentos referindo-se ao "tibunal"). A família de Beatriz rompeu o vínculo com João após a separação, dando total apoio a ela durante o processo.

Os dados do Método Rorschach evidenciaram que Beatriz foi extremamente resistente frente à tarefa. Em função disso, os dados foram analisados com cautela, pois foi possível perceber uma intenção consciente de não se mostrar através do teste. Os resultados apresentados foram escassos e as respostas de forma pura predominaram. Ainda assim, o índice de déficit relacional foi positivo, revelando uma inaptidão para os 
aspectos relacionais, com distorção na percepção e discriminação do outro.

Beatriz apresentou um número elevado de respostas personalizadas no Rorschach, demonstrando aspectos de um autoritarismo infantil em sua organização psicológica. Exner e Sendín (1999), ao discorrerem sobre situações de simulação e fingimento no Rorschach, destacaram que as respostas personalizadas são frequentes em pais envolvidos em disputas de guarda. Este aspecto pareceu estar associado a uma necessidade de dar o melhor de si e de buscar reassegurar que sua posição no conflito é a mais adequada e correta.

Do ponto de vista qualitativo, Beatriz expôs, na primeira lâmina, sua confusão e sua dificuldade na capacidade de discriminação (Viglione, 2004) ao perceber "uma mistura de uma abelha com um morcego". Para Weiner (2000), a primeira lâmina do Método Rorschach funciona como um estímulo para que a pessoa se apresente como ela é, demonstrando assim, como lida com situações novas e perturbadoras.

Beatriz não apresentou movimentos com pares $\mathrm{e}$ demonstrou ser uma pessoa mais controlada, com dificuldade de externalizar o afeto de forma espontânea. Com isso, foi possível cogitar a hipótese de que tenha dificuldades em estabelecer relações maduras, pois suas vivências infantis remetem a vínculos de dependência e desorganização frente ao ambiente familiar e às figuras materna e paterna.

O Método Rorschach de João evidenciou índices de depressão e de constelação de suicídio positivos. A constelação de suicídio pareceu estar relacionada a sentimentos de desesperança frente ao distanciamento dos filhos. Não ficou evidente qualquer tipo de ideação suicida durante sua avaliação. João apresentou indicadores que remetem à presença de pensamentos intrusivos, provavelmente associados a revivências de situações traumáticas em que esteve envolvido.

Em seu protocolo apareceram respostas personalizadas, demonstrando, assim como sua exmulher, características autoritárias infantis. Foram encontrados indicadores que revelaram dificuldades no controle dos impulsos. Esses dados são sugestivos de uma personalidade de alguém que também parece apresentar dificuldades em estabelecer relações maduras.

Os indicadores do Rorschach revelaram ainda movimentos com pares como: "homem e mulher se beijando", "um casal brigando, com um bercinho no meio e cada um puxando para um lado”. A análise qualitativa dessas respostas evidenciou o impacto que o litígio vem exercendo em seu psiquismo. Na primeira lâmina, percebeu "mãozinhas de criança querendo colo, erguendo os bracinhos". Durante o inquérito do teste, disse que se lembrava de sua filha, já que a mesma costumava the pedir colo daquela forma.

A união desse casal chamou atenção por apresentarem um relacionamento muito explosivo. Ambos pareceram funcionar como disparadores das vulnerabilidades do outro. Desta forma, enfrentavam-se quase que diariamente como duas crianças enfurecidas. É possível supor que ambos contribuíram para que o relacionamento não prosperasse. Porém, não foram encontrados elementos que justificassem o afastamento de João dos filhos.

É provável que Beatriz esteja repetindo um padrão de relação mais infantilizada com seus filhos, já que afirmou que deseja ser muito mais a "amiga" do que a mãe. Seus motivos para afastar o ex-cônjuge da convivência com os filhos pareceram estar ligados a sentimentos de raiva que ela própria sente dele, não conseguindo discriminar os sentimentos $\mathrm{e}$ as necessidades dos filhos.

\section{Caso 3: Taís e Marcelo}

Taís e Marcelo se conheceram muito jovens, ela com 15 e ele com 20 anos. Após um mês de relacionamento, foram morar juntos, na casa dos pais dela. Taís engravidou do filho Igor aos 16 anos. O menino estava com 6 anos na ocasião da avaliação. Durante o relacionamento, o casal teve muitas brigas, pois ela desconfiava que Marcelo não fosse fiel. Já Marcelo contou que sua ex-mulher era muito ciumenta e que foi isso que fez com que o relacionamento não desse certo. No momento da avaliação, estavam envolvidos em um processo de regulamentação de visitas movido pela mãe de Marcelo.

A infância de Marcelo foi marcada pela perda precoce de seu pai, quando tinha 6 anos de idade. A situação foi bastante traumática, um acidente que até hoje não foi bem esclarecido para ele. Naquela ocasião, "ninguém falou nada para mim, eu não sabia o que estava acontecendo". Antes de perder seu pai, sentia-se muito ligado a ele e disse que, quando criança, costumava ir ao armazém e voltava ao ouvir o "assobio" de seu pai.

O relacionamento com sua mãe foi descrito como bastante próximo, já que a mãe passou a criar os três 
filhos sozinha. Marcelo referiu: "ela foi amiga, foi uma mãe, foi pai, me deu amor, carinho". Costumava conversar com sua mãe, falar sobre o que sentia: "a minha mãe sempre foi mais para mim, até hoje". Narrou bastante sofrimento com a ausência do pai, principalmente em datas especiais, mencionando "Deus foi cruel, esse é meu sentimento". Marcelo refez sua vida, tem um novo relacionamento e mora "na casa dela".

Já Taís narrou uma infância "tranquila" em que se sentia mais próxima de sua mãe, já que seu pai "trabalhava muito" e não se envolvia na educação das filhas. Relatou a relação com sua mãe dizendo que ela sempre foi sua amiga, dava-lhe conselhos, destacando que "quando eu queria pedir alguma coisa era só com a minha mãe". Até os 12 anos de idade costumava dormir na cama de seus pais com certa frequência. A relação com a mãe passou a ficar abalada quando Taís se envolveu com Marcelo. Seus pais não aceitavam sua união com ele. Porém, sentia-se "cega e apaixonada" e passou a não escutar os conselhos de sua mãe.

Beatriz acabou engravidando de forma precoce, ainda na adolescência. Mesmo assim, ambos afirmaram que o filho foi desejado e planejado. O menino Igor nasceu com problemas cardíacos, necessitando de cuidados especiais desde o nascimento. Durante seus relatos Taís desqualificou a figura de sua ex-sogra diversas vezes, denotando uma competitividade com ela. No momento da avaliação, estava em um novo relacionamento e o rapaz estava morando na casa dos pais dela. Enfatizou diversas vezes o quanto seu filho gostava de seu novo companheiro, fazendo questão de chamá-lo de "pai".

O relacionamento de Taís e Marcelo durou três anos e terminou, segundo ela porque Marcelo batia nela e no filho. A separação foi conturbada, com muitas brigas e vários registros policiais. Taís contou que a maior briga ocorreu por causa de uma geladeira que estava sendo disputada entre os dois. Na primeira vez em que Marcelo buscou o filho para uma visita, Taís escreveu em um papel tudo o que o menino podia e não podia fazer e comer e fez Marcelo assinar. Para ela, Marcelo e sua mãe queriam andar com seu filho "para cima e para baixo como um troféu".

O rompimento final ocorreu em uma ocasião em que brigaram e, segundo ela, ele rasgou suas roupas. Taís acusou o ex-marido de usar drogas e ser agressivo. Contou que ele não era um bom pai, que batia e não cuidava bem do menino. Já Marcelo queixou-se da influência negativa de sua ex-sogra dizendo que ela era muito "temperamental" e que depois da separação ficou muito difícil ver seu filho.

Os indicadores de Alienação Parental apareceram de forma clara no discurso de Taís. Ao narrar o relacionamento de seu filho com o pai e com a família paterna os desqualificou, mostrando acreditar que o contato com eles não fazia nenhuma falta ao menino. Referiu-se o tempo todo a "aquela gente", afirmando que eles "não amam o Igor", dando a entender que o processo judicial foi movido apenas "para fazer desaforo". Quando o relacionamento terminou, os pais de Taís ficaram muito abalados, passando a rechaçar a ideia da aproximação de Marcelo com o filho.

Os indicadores do Método Rorschach de Marcelo revelaram um índice de depressão positivo, constelação de suicido positiva e déficit relacional positivo. Esses componentes são sugestivos de um estado depressivo com sentimentos de desesperança, associados à falta de recursos internos para lidar com a complexidade das vivências da separação.

Os dados do teste demonstraram características de uma organização de personalidade em que as demandas do mundo externo são maiores do que os recursos do mundo interno. Foram constatados sentimentos de baixa autoestima e elevada ansiedade. Neste sentido, ficou claro que as emoções estavam atrapalhando o seu funcionamento psicológico. Outros indicadores sugeriram a presença de uma distorção na percepção do outro, com dificuldades na capacidade de discriminação.

A análise qualitativa de suas respostas evidenciou uma diminuição significativa dos movimentos com pares. Marcelo só apresentou uma resposta desse tipo e ainda assim foi de um movimento inanimado: "fogos de artifício explodindo". Ao narrar suas percepções na lâmina quatro, a qual Weiner (2000) relacionou com a figura paterna, Marcelo viu "um corpo humano aberto" e "uma folha rasgada". Essas respostas denotaram como seus objetos internos encontravam-se identificados com uma figura paterna destruída. Por ter tido uma vivência de perda precoce e traumática do pai, pode-se supor que essa situação ainda se encontra viva em seu psiquismo.

Já o protocolo do Rorschach de Taís demonstrou características narcisistas em seu funcionamento psicológico. Apesar de não apresentar um número baixo de respostas de figuras humanas inteiras, apresentou um número expressivo de figuras humanas 
de menor qualidade. Pode-se cogitar a hipótese de que Taís tenha uma visão do outro influenciada pelo seu narcisismo, o que não deixa de ser uma distorção na percepção do outro.

Apareceram ainda, em suas respostas, indicadores de que Taís exerça um controle maior sobre suas emoções. Neste sentido, pode ser mais rígida quanto a processos de mudança. Esse dado, associado a um componente de narcisismo, demonstrou que ela sempre se acha correta, sendo menos sensível à posição dos outros. Isso ocorre por ela não se perceber com problemas, o que pode gerar dificuldade de empatia e de perceber as necessidades dos outros.

Do ponto de vista qualitativo, foi possível perceber, em todo seu protocolo, respostas simples tais como: "morcego", "borboleta", "um sapato", "dois pássaros". Taís apresentou movimentos com pares. Porém, alguns desses movimentos apresentaram relações implausíveis como "bichos se dando as mãos". Para Exner e Sendín (1999), respostas como estas representam uma integração irracional dos dados, sugerindo desorganização e imaturidade.

Este caso ilustra bem a união de "duas crianças", duas pessoas muito jovens e pouco preparadas para as demandas do mundo adulto. Ela com uma vivência de falta de limites, passando da cama dos pais para a cama do marido, já que aos doze anos dormia com os pais e aos dezesseis já estava grávida. Neste sentido, verificou-se um vínculo pouco estruturado, indiscriminado e com poucos limites. Já Marcelo pareceu ter uma relação muito intensa com sua mãe, passando a viver com as mulheres, com as quais se relaciona, uma relação de dependência.

É possível que, ao enxergar em sua ex-sogra uma concorrente ao amor de seu companheiro e de seu filho, Taís tenha sido tomada por sentimentos hostis, passando a rechaçar totalmente a presença do exmarido na vida do filho. Ao sentir que o menino poderia vincular-se com a família paterna, sentiu-se diretamente atingida em seu narcisismo, já que mencionou diversas vezes "eles querem o meu filho". Desta forma, a Alienação Parental pareceu ser um caminho natural para esta mãe imatura e egocêntrica, encontrando terreno fértil para suas atitudes na passividade de Marcelo.

\section{Convergências entre os casos}

Os três casos participantes deste estudo tinham histórias de relacionamentos conturbados, permeados por imaturidade. As mães concebiam a maternidade com uma noção de propriedade. Na verdade, utilizavam as crianças na tentativa de exercer um controle sobre o relacionamento de seus filhos com os pais. Em contrapartida, todos os pais avaliados apresentaram vivências depressivas em relação ao afastamento dos filhos, incrementadas por sentimentos de desesperança, denotando não acreditar na reaproximação com eles.

A literatura tem apontado que as mães costumam ocupar o papel de alienadoras e suas características individuais contribuem para a ocorrência do fenômeno da Alienação Parental (Bala, Hunt \& MacCarney, 2010; Berns, 2001; Clawar \& Rivlin, 1991; Calabrese, Miller \& Dooley, 1987; Dunne \& Hedrick, 1994; Johnston, 2003). Nos três casos analisados, as mães mantiveram conduta alienadora em relação aos filhos. O discurso observado foi unilateral, com posicionamentos rígidos, demonstrando inabilidade para os aspectos relacionais.

Dos seis participantes do estudo, cinco narraram histórias de intensa ligação com suas figuras de apego durante a infância, a maioria delas representada pela figura materna. Pôde-se observar que essas relações foram regidas por um padrão simbiótico de relacionamento. As principais características de estrutura de personalidade dos participantes encontramse na Tabela 2.

Os dados expostos na Tabela 2 demonstram algumas características importantes. Foi observado um padrão de rompimento de vínculos precoce, com histórias de vínculos simbióticos. Desta forma, a ansiedade predominante nas mães foi a de perda do objeto, vinculada a um núcleo simbiótico. Os pais também apresentaram ansiedade de perda do objeto, mas foi possível perceber que esta ansiedade estava associada às vivências da separação e do afastamento dos filhos. Os mecanismos de defesa observados nas genitoras alienadoras foram de natureza primitiva, como a clivagem e a identificação projetiva. Já os pais, apresentaram defesas como a negação e a repressão. Os dados do Rorschach evidenciaram particularidades em cada participante, destacando-se a presença de distorção na percepção do outro, narcisismo e prejuízo na capacidade de discriminação.

Em relação às mães ditas alienadoras observou-se um padrão regressivo no estabelecimento das relações objetais. Seus vínculos iniciais foram permeados por dependência e indiscriminação. Desta forma, não desenvolveram uma capacidade de manter vínculos afetivos maduros na vida adulta. Esse padrão assemelha-se ao que Bergeret (1988) descreveu como relação de objeto anaclítica. Esse é um tipo de relação 
Tabela 2

Principais características da estrutura de personalidade dos participantes do estudo

\begin{tabular}{|c|c|c|c|c|}
\hline Nome & Relações Objetais & $\begin{array}{l}\text { Ansiedade } \\
\text { Predominante }\end{array}$ & Principais Defesas & Outros achados do Rorschach \\
\hline Dora & $\begin{array}{l}\text { História de rompimento precoce } \\
\text { dos vínculos familiares e relação de } \\
\text { dependência com a figura materna. }\end{array}$ & $\begin{array}{l}\text { De perda do objeto } \\
\text { vinculada a um núcleo } \\
\text { simbiótico. }\end{array}$ & $\begin{array}{l}\text { Negação, clivagem } \\
\text { e Identificação } \\
\text { projetiva. }\end{array}$ & $\begin{array}{l}\text { Depressão, distorção na } \\
\text { percepção do outro, imaturidade } \\
\text { e prejuízo na capacidade de } \\
\text { discriminação. }\end{array}$ \\
\hline José & $\begin{array}{l}\text { História de perda precoce da figura } \\
\text { paterna, com intensa ligação à } \\
\text { figura materna. }\end{array}$ & $\begin{array}{l}\text { Ansiedade relacionada } \\
\text { a vivências de } \\
\text { acusação. }\end{array}$ & $\begin{array}{l}\text { Evitação e } \\
\text { repressão. }\end{array}$ & $\begin{array}{l}\text { Depressão, desesperança, baixa } \\
\text { autoestima e distorção na } \\
\text { percepção do outro. }\end{array}$ \\
\hline Beatriz & $\begin{array}{l}\text { História de ligação simbiótica com o } \\
\text { irmão, figura substitutiva da mãe. }\end{array}$ & $\begin{array}{l}\text { De perda do objeto } \\
\text { vinculada a um núcleo } \\
\text { simbiótico. }\end{array}$ & $\begin{array}{l}\text { Negação, clivagem } \\
\text { e identificação } \\
\text { projetiva. }\end{array}$ & $\begin{array}{l}\text { Déficit relacional, distorção na } \\
\text { percepção do outro, prejuízo na } \\
\text { capacidade de discriminação e } \\
\text { autoritarismo infantil. }\end{array}$ \\
\hline João & $\begin{array}{l}\text { História de separação dos pais na } \\
\text { adolescência. }\end{array}$ & $\begin{array}{l}\text { De perda do objeto com } \\
\text { vivências associadas à } \\
\text { separação. }\end{array}$ & Evitação & $\begin{array}{l}\text { Depressão, desesperança, } \\
\text { dificuldade no controle dos } \\
\text { impulsos e autoritarismo infantil. }\end{array}$ \\
\hline Tais & $\begin{array}{l}\text { História de dependência da figura } \\
\text { materna. }\end{array}$ & $\begin{array}{l}\text { De perda do objeto } \\
\text { vinculada a um núcleo } \\
\text { simbiótico. }\end{array}$ & $\begin{array}{l}\text { Negação, clivagem } \\
\text { e projeção. }\end{array}$ & $\begin{array}{l}\text { Narcisismo, rigidez para } \\
\text { mudanças, dificuldade na } \\
\text { capacidade de discriminação e } \\
\text { imaturidade. }\end{array}$ \\
\hline Marcelo & $\begin{array}{l}\text { História de perda precoce da figura } \\
\text { paterna, com intensa ligação à } \\
\text { figura materna. }\end{array}$ & $\begin{array}{l}\text { De perda do objeto } \\
\text { associada às vivências } \\
\text { da separação. }\end{array}$ & $\begin{array}{l}\text { Evitação e } \\
\text { negação. }\end{array}$ & $\begin{array}{l}\text { Depressão, déficit relacional, } \\
\text { sentimentos de desesperança, } \\
\text { autoestima baixa e dificuldades } \\
\text { na capacidade de discriminação. }\end{array}$ \\
\hline
\end{tabular}

de dependência que é vivida a dois, na qual a entrada de um terceiro pode ser vista como uma ameaça.

Para Bergeret (1988), na organização limite, a relação de objeto permanece centrada na dependência anaclítica do outro. Não se trata de um rompimento do ego, mas de uma reação defensiva. O ego deforma-se em algumas de suas funções e pode operar em dois registros diferentes: um adaptativo em situações em que não existam ameaças ao indivíduo e de outra parte, um registro anaclítico, desde que haja a ameaça de perda do objeto.

A história das três mães ditas alienadoras pode ser comparada ao que a literatura descreve como patologias ou organizações limítrofes. Essas organizações caracterizam-se por apresentarem angústia de separação ou perda do objeto, difusão de identidade, clivagem, impulsividade, narcisismo, agressividade e impulsividade (Bergeret, 1988; Kernberg, 1995). Foram observadas características compatíveis com algumas dessas descrições nas genitoras ditas alienadoras. Em todas elas, um núcleo simbiótico foi identificado como a base de suas dificuldades, demonstrando assim que suas primeiras vivências geraram representações de indiscriminação e dependência, padrão repetido na relação com os filhos.

Os pais ditos alienados também apresentaram histórias de rompimento de vínculos. Dois deles de forma precoce, com a perda real do pai. João, não perdeu seu pai, porém o descreveu como um homem alcoolista. É possível que, mesmo com a presença desse pai, a representação gerada foi de uma ausência, um pai que não estava em plenas condições de exercer a paternidade. Nos três casos analisados, os genitores apresentaram vínculos frágeis com a figura paterna. Todos os genitores apresentaram um resultado de depressão no Rorschach, o que demonstrou que o 
fenômeno da Alienação Parental, o afastamento dos filhos, os conflitos no processo judicial podem ter contribuído para esse resultado. Eles apresentaram também, sentimentos de desesperança frente à retomada do contato com seus filhos.

As estratégias utilizadas pelas mães para alienar os filhos do convívio com os pais foram semelhantes às descritas em outros estudos (Baker \& Darnall, 2006; Bow, Quinnell \& Zarof, 2002; Dias, 2006; Dunne \& Hedrick, 1994; Gardner, 1987; Vassilou \& Cartwright, 2001). Destacou-se a presença de argumentos ensaiados, falsa denúncia de abuso sexual, desqualificação do genitor alienado com discursos carregados de elementos hostis.

Os resultados do presente estudo permitem uma reflexão acerca de uma dinâmica relacional. Em todos os casos, foi possível perceber a conduta alienadora das mães, mas tanto as histórias colhidas, como os resultados do Método Rorschach, demonstraram que os pais também apresentaram particularidades e dificuldades que, de certa forma, contribuíram para a existência do fenômeno da Alienação Parental. Nessa perspectiva, não existe uma vítima ou um culpado e sim uma dificuldade de todos os envolvidos de estabelecer uma outra forma de relacionamento.

\section{CONSIDERAÇÕES FINAIS}

Os resultados obtidos na análise dos estudos de caso vêm ao encontro de alguns aspectos descritos na literatura. A Alienação Parental tem sido compreendida como um processo em que todos os envolvidos têm uma participação. Desta forma, observou-se que não é possível reduzir a compreensão do fenômeno na perspectiva da existência de uma vítima e um culpado.

Em todos os casos, observou-se uma dificuldade no estabelecimento de relações maduras e estáveis, e relações objetais permeadas por perdas precoces, conflitos e ambivalências. Desta forma, os vínculos constituídos pelos participantes mostraram-se frágeis, instáveis e sujeitos a rupturas. Além disso, foi observada, nas mães ditas alienadoras, a presença de defesas primitivas e intensa ansiedade de separação. Os resultados das mães alienadoras apontaram para características compatíveis com as das organizações limítrofes de personalidade.

Outro fator que mereceu destaque, nesta pesquisa, foi a identificação de um núcleo simbiótico nas mães ditas alienadoras. Esse núcleo agiu como força motivadora para suas dificuldades relacionais. Este é um achado que confirma o que vem sendo apontado na literatura: as características individuais dos envolvidos têm importância significativa para a compreensão do fenômeno.

Em relação aos pais ditos alienados, todos apresentaram indicadores positivos para depressão com um sentimento de desesperança intenso. Foi possível observar, em todos os casos analisados, que as dificuldades de relacionamento com as mães ditas alienadoras eram anteriores à separação. Os relacionamentos eram permeados por características de imaturidade, pouca discriminação e, em dois casos, com a presença de impulsividade.

É relevante considerar a importância da realização de novos estudos qualitativos que possam contribuir para um melhor esclarecimento do fenômeno da Alienação Parental e suas particularidades. Como os achados dizem respeito a uma dinâmica relacional, seria interessante que novos estudos explorassem essa questão, avaliando mais profundamente a formação e o rompimento dos vínculos afetivos dos envolvidos no fenômeno.

\section{REFERÊNCIAS}

Aguilar, J.M. (2007). Síndrome de alienación parental: hijos manipulados por um cónyuge para odiar al outro ( $4^{\circ} \mathrm{ed}$.). España: Almuzara.

Bala, N., Hunt, S. \& MacCarney, C. (2010). Parental alienation Canadian court cases - 1989-2008. Family Court Review, 48, 164-179.

Baker, A. J. L. \& Darnall, D. (2006). Behaviors and Strategies Employed in Parental Alienation: A Survey of Parental Experiences. Journal of Divorce \& Remarriage, 45, 75-99.

Bergeret, J. (1988). Personalidade normal e patológica ( $2^{\circ}$ ed.). Porto Alegre: Artes Médicas.

Bernet, W. (2008). Parental Alienation Disorder and DSM-V. The American Journal of Family Therapy, 36, 349-366.

Berns, S. (2001) Parental alienation syndrome in the family court: magic bullet or poisoned chalice? Australian Journal of Family Law, 15, 191-214.

Bone, M.J. (2003). Parental Alienation Syndrome: Examining the Validity Amid Controversy. The Family Law Section, 1, 24-27.

Bow, J. N., Quinnell, F. A., Zaroff, M., \& Assemany, A. (2002). Assessment of sexual abuse allegations in child custody cases. Professional Psychology: Research and Practice, 33, 566-575.

Calabrese, R. M.; Miller, J. W. \& Dooley, B. (1987). The identification of alienated parents and children: Implications for school psychologists. Psychology in the Schools, 24, 145-150.

Centro de Políticas Sociais da Fundação Getulio Vargas. 
(2012). Renda e Bem-Estar. Recuperado em 20 de março de 2012, em http://cps.fgv.br/renda-bem-estar

Clawar, S. S. \& Rivlin, B. V. (1991). Children held hostage: Dealing with programed and brainwashed children. Ilinois: American Bar Association.

Cruz, R. M., Maciel, S. K. \& Ramirez, D. C. (2005). O Trabalho do psicólogo no campo jurídico. São Paulo: Casa do Psicólogo.

Cunha, J A. (2003). Psicodiagnóstico - V. (5 $\left.5^{\mathrm{a}}\right)$. Ed. Porto Alegre: Artmed.

Darnall, D. (1997). New definition of parental alienation. What is the difference between parental alienation (PA) and parental alienation syndrome (PAS)? Recuperado em 15 dezembro, 2009, em $\mathrm{http} / / \mathrm{www}$. parentalalienation.com/articles/parentalalienation-defined.html

Darnall, D. (2010). Beyond divorce casualities: reunifying the alienated family. Plymouth, UK : Taylor Trade.

Dias, M.B.D. (2006). Da alienação parental, o que é isso? Jus Navegandi. Recuperado em 7 dezembro, 2009, em HTTP//WWW.cefipoa.com.br/artigos.php?id=4\&*h*sess $\mathrm{d}=\mathrm{b} 1041 \mathrm{eb} 1 \mathrm{c} 62568321 \mathrm{~b} 9 \mathrm{bf} 8095 \mathrm{~d} 07097 \mathrm{c}$

Dunne, J. \& Hedrick, M. (1994). The parental alienation syndrome: an analysis of sixteen selected cases. Journal of Divorce and Remarriage, 21, 21-38.

Emery, R. (2005). Parental alienation syndrome: Proponents bear the burden of proof Family. Court Review, 43, 8-13.

Escudero, A., Aguilar, L. \& La Cruz, J. D. (2008). La lógica Del síndrome de alienación parental de Gardner (SAP): terapia de La amenaza. Rev. Assoc. Neuropsiq. 28, 283305.

Exner, J.E. (1999). Manual de classificação do Rorschach para o Sistema Compreensivo. São Paulo: Casa do Psicólogo.

Exner, J.E. \& Sendín C. (1999). Manual de interpretação do Rorschach para o Sistema Compreensivo. São Paulo : Casa do Psicólogo.

Flick, U. (2009). Introdução à pesquisa qualitativa. Porto Alegre: Artmed.

França, F. (2004). Reflexões sobre a Psicologia Jurídica e seu panorama no Brasil. Psicologia: Teoria e Prática, 6 (1), 73-80.

Freud, S. (1916). Conferencias de introducción al psicoanálisis (v.16). Em Obras completas (1994). Argentina: Amorrortu editores.

Gardner, R. A. (1987). The parental alienation syndrome and differentiation between fabricated and genuine child sex abuse. New Jersey: Creative Therapeutics.

Gardner, R.A. (1998). The parental alienation syndrome: a guide for mental health and legal professionals. New jersey: Creative Therapeutics.

Gordon, R. M., Sroffey, R. \& Bottineli, J. (2008). MMPI-2 findings of primitive defenses in alienating parents. The American Journal of Family Therapy, 36, 211-228.

Gudjonsson, G. (1983). Suggestibility, intelligence, memory recall and personality: an experimental study. British Journal Psychiatric, 142, 35-37.
Johnston, J. R. (2003). Parental alignments and rejection: an empirical study of alienation children of divorce. Journal of the American Academy of Psychiatry and the Law, 31, $158-170$.

Kelly, J. B. \& Johnston, J. R. (2001). The alienated child: A reformulation of parental alienation syndrome. Family Court Review, 39, 249-266.

Kernberg, O. (1995). Transtornos graves de personalidade: Estratégias psicoterapêticas. Porto Alegre: Artes Médicas.

Kopetski, L. M. (1998). Identifying cases of parent alienation syndrome, part II. The Colorado Lawyer, 7, 61-67.

Lago, V.M \& Bandeira, D.R. (2009). A psicologia e as demandas atuais do direto de família. Psicologia Ciência e Profissão, 29 (2), 290-305.

Nascimento, R,S.G.F. (2010). Sistema compreensivo do Rorschach: teoria, pesquisa e normas para a população brasileira. São Paulo: Casa do Psicólogo.

Rovinki, S. L. R. (2007). Fundamentos da perícia psicológica forense. São Paulo: Vetor.

Rovinki, S. L. R. (2011). O Rorschach e as técnicas projetivas no contexto forense. Em Villemor-Amaral, A.E \& Werlang, B.S.G. Atualizações em métodos projetivos para avaliação psicológica. (pp. 107-119). Casa do Psicólogo: São Paulo.

Singer, J., Hoppe, C.F., Lee, S.M. \& Walters M.G. (2008). Child custody litigants: Rorscach data from a large sample. In Gacono, C.B. \& Evans, F.B. The handbook of forensic Rorschach assessment. New York: Routledge.

Stein, L. M., \& Pergher, G. K. (2001). Criando falsas memórias em adultos por meio de palavras associadas. Psicologia: Reflexão e Crítica, 14, 353-366.

Stein, L. M.; Feix, L. \& Rohenkohl. (2006). Avanços metodológicos no estudo das falsas memórias: construção e normatização do procedimento de palavras associadas à realidade brasileira. Psicologia: Reflexão e Crítica, 19, 196-205.

Stokkers, R. \& Kormos, H. (2005). Parental Alienation Syndrome in the Netherlands. The American Journal of Family Therapy, 33, 303-317.

Vassilou, D. \& Cartwright, G. F. (2001). The lost parents perspective on parental alienation syndrome. The American Journal of Family Therapy, 29, 181-191.

Viglione, D.J. (2004). Rorschach coding solutions- a reference guide for the comprehensive system. California: Trade Printing Services.

Villemor-Amaral, A.E. \& Pasqualine-Casado, L.P. (2006). A cientificidade das técnicas projetivas em debate. PsicoUSF, 11(2), 185-193.

Weiner, I. (2000). Princípios da interpretação do Rorschach. São Paulo: Casa do Psicólogo.

Yin, R.K. (2005). Estudo de caso: planejamento e métodos. Porto Alegre: Bookman. 
Recebido em: 10/07/2013 Última Revisão em: 10/10/2015

Aceito em: 20/10/2015

\section{Notas:}

1 Especialista em Psicoterapia de Orientação Psicanalítica pela Fundação Universitária Mario Martins, Mestre em Psicologia Clínica pela Unisinos e Psicóloga Judiciária do Tribunal de Justiça do Rio Grande do Sul.

2 Doutora em Psicologia Clínica, Professora e Pesquisadora do Programa de Pós-Graduação em Psicologia Clínica da Unisinos, Rio Grande do Sul. E-mail: vramires@unisinos.br. 